\title{
Retrospective analysis of 20 cases of refractory Hodgkin's lymphoma
}

\author{
H. L. YANG*, Y. Z. ZHANG*, Y. Z. JIANG, X. F. WANG, Z. CAO
}

Department of Hematology, Tianjin Medical University Cancer Institute and Hospital, Key Laboratory of Cancer Prevention and Therapy, National Cancer Research Center, Ti-Yuan-Bei, Huan-Hu-Xi-Road, Tianjin 300060 PR China

*Correspondence: 18622221239@163.com,oncology2005@163.com

Received January 24, 2017 / Accepted April 10, 2017

\begin{abstract}
We investigate the clinical characteristics, prognosis and treatment of relapsed and refractory Hodgkin's lymphoma. Twenty patients with relapsed and refractory Hodgkin lymphoma were treated by chemotherapy or autologous stem cell transplantation in our hospital from April 2006 to August 2012. The retrospective analysis of the records from the 20 patients reflected both 5-year overall survival (OS) and progression-free survival (PFS). The overall effectiveness was $80 \%$ for the 20 patients. The 5-year overall survival rate and 5-year progression-free survival rate were $73.5 \%$ and $62.7 \%$, respectively. Therefore, comprehensive treatment should be actively utilized in the case of invalid second-line regimen for the refractory HL patients.
\end{abstract}

Key words: relapsed and refractory Hodgkin's lymphoma, prognosis, autologous stem cell transplantation

Hodgkin lymphoma (HL) originates from the B lymphocyte malignancies, characterized by the typical Reed-Sternberg (R-S) cells in lymphoid tissue. It is more common in Europe and the United States than in Asian countries [1]. Compared with non-Hodgkin's lymphoma, the incidence of HL is lower, while the cure rate of $\mathrm{HL}$ is relative higher. Although a satisfactory cure rate could be achieved by radiotherapy or combination chemotherapy, $20 \%$ of the patients would develop refractory and recurrent HL [2]. In the patients in the advanced stage, 30\% of them appear the disease progressing, while 15\%existprimary drug resistance [3].How to early identify refractory patients is important to improve the cure rate. The high-risk patients who are not sensitive to conventional chemotherapy could be treated with high doses of chemotherapy or autologous hematopoietic stem cell transplantation. On the contrary, low-risk patients should be identified to avoid adverse effects caused by excessive chemotherapy [3]. Both clinical and molecular markers have been applied in the HL prognosis at diagnosis or in the relapsed/refractory setting. Previous study reported the adverse prognostic factors of HL patients as follows: male, age $>45$, albumin $<40 \mathrm{~g} / \mathrm{L}$, hemoglobin $<105 \mathrm{~g} / \mathrm{L}$, white blood cell count $\geq 15 \times 10^{9} / \mathrm{L}$, lymphocyte count $<0.6 \times 10^{9} / \mathrm{L}$ or proportion $<8 \%$ and in stage IV [4]. For advanced patients, the international prognostic score (IPS) was often used as the evaluation criterion, classifying the advanced HL patients into low-risk group (IPS 0-2) and high-risk group (IPS $\geq 3$ ). However, there is no consensus on refractory and recurrent HL patients. LYSA (LYmphoma Study Association) reported poor prognostic factors as relapse time $<1$ year and clinical stage IIIIV during recurrence [2]. The extra nodal lesions and group B symptoms were added to the prognostic factors according to the Memorial Sloan Kettering Cancer Center (MSKCC) [5].

Currently, there are no new agents for the recurrent and refractory patients since 1970s. For patients relapsed after initial treatment, salvage chemotherapy followed by ASCT is the standard of care for the sensitive patients. For patients relapsed after second-line therapy, the optimal treatment remains unknown [6,7]. Exploring the effective treatment of these patients has gained widely concern. Here we report and summarize the clinical features of 20 cases of refractory Hodgkin lymphoma patients.

\section{Patients and methods}

Patient selection. Patient data in the Affiliated Tumor Hospital of Tianjin Medical University (Tianjin, China) were retrospectively reviewed. We enrolled 20cases of refractory classic Hodgkin lymphoma (CHL) patients with complete follow-up from April 2006 to August 2012. All patients were diagnosed based on pathological examination. 
Data collection. Patient baseline and clinical data, including age, sex, disease stage, laboratory tests (blood routine; blood metabolic panel: liver and kidney function, LDH and $\beta 2$ microglobulin; EB virus detection; bone marrow biopsy and biopsy) and imaging examination (ultrasound for superficial lymph nodes, CT or PET-CT for chest, abdomen and). All patients gave written informed consent, and approval for the study was obtained from the Institutional Review Board, which conformed to the standards of the Declaration of Helsinki.

Patient treatment. Of the 20 cases, 3 early recurrent patients (recurrence occurred less than 6 months after treatment) and 2 refractory patients (curative effect of SD after 2 cycles of ABVD scheme) received Beacopp chemotherapy (bleomycin $10 \mathrm{mg} / \mathrm{m}^{2}, \mathrm{~d} 8$, etoposide $200 \mathrm{mg} / \mathrm{m}^{2}, \mathrm{~d} 1-3$, doxorubicin $35 \mathrm{mg} /$ $\mathrm{m}^{2}, \mathrm{~d} 1$, cyclophosphamide $1.2 \mathrm{~g} / \mathrm{m}^{2}, \mathrm{~d} 1$, vincristine $1.4 \mathrm{mg} / \mathrm{m}^{2}$, $\mathrm{d} 8$, methyhydrazine $100 \mathrm{mg} / \mathrm{m}^{2}$, $\mathrm{d} 1-7$, prednisone $40 \mathrm{mg} / \mathrm{m}^{2}$, $\mathrm{d} 1-14,21$ days as one course of treatment).

Of the 15 late recurrent patients (recurrence occurred more than 6 months after treatment), 13 received ABVD chemotherapy (doxorubicin $25 \mathrm{mg} / \mathrm{m}^{2}$, d1, 15 ; bleomycin $10 \mathrm{mg} / \mathrm{m}^{2}$, d1, 15 ; vinblastine $6 \mathrm{mg} / \mathrm{m}^{2}, \mathrm{~d} 1,15$; dacarbazine $375 \mathrm{mg} / \mathrm{m}^{2}$, $\mathrm{d} 1,15)$, and the other 2 patients received the combination of rituxan $\left(375 \mathrm{mg} / \mathrm{m}^{2}, \mathrm{~d} 0\right)$ with ABVD scheme. During the period of chemotherapy, the granulocyte colony stimulating factor was subcutaneous injected if the white blood cell count is lower than $2.0 \times 10^{9} / \mathrm{L}$.

Based on the treatment response, complete remission (CR) patients got autologous hematopoietic stem cell transplantation (ASCT) after pretreatment of BEAM (BCNU $300 \mathrm{mg} / \mathrm{m}^{2}$, $-6 \mathrm{~d}, \mathrm{VP}-16100 \mathrm{mg} / \mathrm{m}^{2},-5 \mathrm{~d} \sim-2 \mathrm{~d}$, CTX $1.5 \mathrm{~g} / \mathrm{m}^{2},-5 \mathrm{~d} \sim-2 \mathrm{~d}$, Arac $100 \mathrm{mg} / \mathrm{m}^{2}, \mathrm{q} 12 \mathrm{~h}-5 \mathrm{~d} \sim-2 \mathrm{~d}$ ) or CBV (CTX $1.5 \mathrm{~g} / \mathrm{m}^{2},-6 \mathrm{~d} \sim$ $-3 \mathrm{~d}, \mathrm{BCNU} 300 \mathrm{mg} / \mathrm{m}^{2},-6 \mathrm{~d}, \mathrm{VP}-16150 \mathrm{mg} / \mathrm{m}^{2}$, q12h $-6 \mathrm{~d} \sim 4 \mathrm{~d}$ ). Partial remission (PR) patients might get local radiotherapy.

Efficacy and adverse effects. Thirty days after all treatment, the PET-CT was utilized to evaluate the treatment efficacy. Based on the NCCN 2016 guideline, the treatment response of $\mathrm{HL}$ is divided into $\mathrm{CR}, \mathrm{PR}$, stable disease (SD) and progressive diseases (PD). According to the WHO standard, the acute and subacute adverse cancer drug reactions were also applied to evaluate the adverse effects.

Statistical analysis. All data were analyzed by the SPSS version 18.0 software (SPSS, Chicago, IL, United States). The survival curves were constructed by the Kaplan-Meier method. Overall survival (OS) was defined as the interval from the diagnosis of relapse/refractory HL to death or the end of follow-up. Progression-free survival (PFS) was defined as from the diagnosis of relapse/refractory $\mathrm{HL}$ to $\mathrm{PD}$, death or the end of follow-up.

\section{Results}

Baseline characteristics. There were 11 males (55\%) and 9 females $(45 \%)$. The age ranged from 7 to 68 with the median of 30 years old. Three patients were older than 45 . The pathological types included: nodular sclerosis CHL (NSCHL), mixed cellularity CHL (MCCHL) and lymphocyte-rich CHL (LRCHL). Recurrence occurred in 18 of the patients and 2 were refractory patients. The time to recurrence ranged from 8 to 51 months, with the median time of 22 months.

Clinical features of the patients. Superficial lymph node enlargement was the main clinical manifestation in 18 of the patients, with the cervical lymph nodes mostly involved. The other case started with the mediastinal neoplasm. Eight patients had B symptoms (fever, night sweats, and weight loss). None bone marrow was involved in any patient. Anemia was shown in 7 cases, lactate dehydrogenase (LDH) was increased in 9 cases, and $\beta_{2}$-microglobulin was increased in 2 cases. Sixteen patients got the Karnofsky Performance Status (KPS) greater than 60 points. According to the Ann Arbor staging system, 9 cases were in stage I-II, and 11 cases were in stage III-IV, with the International Prognostic Score (IPS) less than 2. With respect to pathologic types, there were 10 cases of NSCHL, 7 cases of MCCHL and 3 cases of LRCHL. The clinical features of the 20 Hodgkin's lymphoma patients were shown in table 1.

Treatment outcome and short-term effect. In the 20 patients who had completed previous chemotherapy,the median course of chemotherapy was 11 (6-18). Two patients had received previous local radiotherapy. The median course of chemotherapy after the disease recurrence was 6 (4-8). For the 11 patients who achieved CR via chemotherapy after recurrence, the consolidation therapy of ASCT was performed. For the 5 patients with PR, 2 achieved CR and 1 got SD in the 3 patients who received the following radiotherapy, the other 2 continued PR. The overall effectiveness was $80 \%$. One patient got SD, the remaining 3 patients were diagnosed as PD.

Survival outcome. Twenty patients were followed up until August 2015, and no one was lost. The median follow-up

Table 1. The clinical features of the 20 Hodgkin's lymphoma patients

\begin{tabular}{|c|c|c|c|c|c|c|c|}
\hline Pathological types & Cases & $\begin{array}{c}\text { Gender } \\
\text { men/women }\end{array}$ & $\begin{array}{c}\text { Age } \\
<45 / \geq 45\end{array}$ & $\begin{array}{c}\text { Stage } \\
\text { I-II/III-IV }\end{array}$ & $\begin{array}{c}\text { EBER } \\
\text { positive }\end{array}$ & $\begin{array}{c}\text { B symptoms } \\
\text { positive/negative }\end{array}$ & Elevated LDH \\
\hline NSCHL & 10 & $6 / 4$ & $9 / 1$ & $4 / 6$ & 6 & $3 / 7$ & 4 \\
\hline MCCHL & 7 & $4 / 3$ & $6 / 1$ & $4 / 3$ & 4 & $4 / 3$ & 4 \\
\hline LRCHL & 3 & $1 / 2$ & $2 / 1$ & $1 / 2$ & 2 & $2 / 1$ & 1 \\
\hline Total & 20 & $11 / 9$ & $17 / 3$ & $9 / 11$ & 12 & $9 / 11$ & 9 \\
\hline
\end{tabular}


A

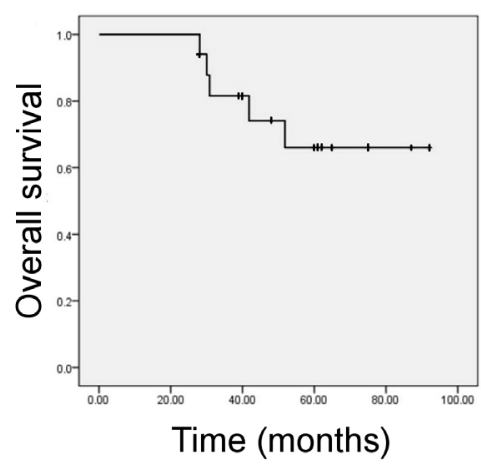

B

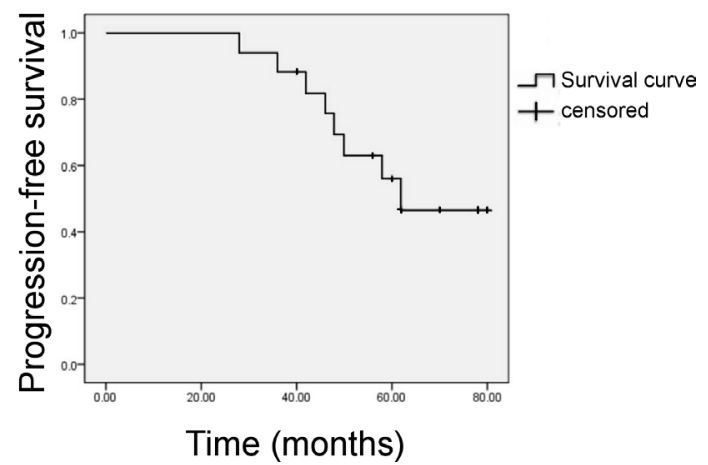

Figure 1. The 5-year overall survival (OS) (A) and progression-free survival (PFS) (B) of the 20 Hodgkin's lymphoma patients

months was 28 (19-60). To the end of follow-up, 13 cases were diagnosed as CR, of which 5 were MCCHL, 6 were NSCHL, and 2 were LRCHL. Two patients were diagnosed as PR, two patient got SD. Three patients died of disease progression. The 5 -year OS and PFS of the 20 patients were $73.5 \%$ and $62.7 \%$, respectively (Figure 1A-B).

Adverse effects related to the treatment. During therapy, III-IV grade myelosuppression occurred in 5 patients. After recombinant human granulocyte colonystimulating factor treatment, the hemogram returned to normal. Shivering and high fever were occurred in 1 case when getting rituximab infusion, and they were alleviated after $5 \mathrm{mg}$ dexamethasone treatment. Impaired liver function (grade I) was shown in 2 cases. Adverse reactions of the digestive system, such as nausea and vomiting, occurred in 14 patients, with 8 cases of grade I, 4 cases of grade II, and 2 cases of grade III. Cardiac toxicity was found in 3 patients, with symptoms as I grade sinus tachycardia. Pulmonary infection (grade II) was shown in 3 cases, which was alleviated after the combination of imipenem and fluconazole treatment (Table 2).

\section{Discussion}

In the 20 cases of refractory patients, the lymph node enlargement was the main clinical manifestation. B symptoms occurred in $40 \%$ patients. With respect to pathological types, the NSCHL accounted for 50\%, the MCCHL accounted for $35 \%$, and the LRCHL accounted for $15 \%$. Of all the patients, $45 \%$ were in stage I-II, and the other $55 \%$ were in stage III-IV. After chemotherapy, the overall effectiveness was $80 \%$.

In this study, there were 11 patients at advanced stage with IPS score $<2$, belonging to the low-risk group. According to the LYSA prognostic factors, however, in the 11 advanced patients, 3 cases $(27.3 \%)$ were with the recurrence time less than 1 year. The fact that less than third of the 11 patients got high risk factors is clearly different from the IPS prognosis prediction. Thus, in the future, HL patients of large sample size from different centers are in great need to better understand the prognosis of HL patients and to improve the overall survival.

Of the 20 patients, 15 advanced patients with recurrence got ABVD chemotherapy, of which 2 cases got combination chemotherapy of rituximab and ABVD. The 5 early refractory cases with recurrence received the second-line regimen of BEACOPP chemotherapy. After treatment, the overall effectiveness was $80 \%$. Currently, there is no consensus on the chemotherapy regimen for refractory HL patients yet [8]. The second-line regimen for refractory $\mathrm{HL}$ patients includes ICE, DHAP, GDP, and Mini-BEAM [9]. Czyz et al. analyzed 132 refractory HL patients underwent ASCT, and reported the 10 -year OS and PFS as $76 \%$ and $66 \%$, respectively [10]. They summarized that ASCT should be utilized for the refractory HL patients. In this study, the 11 patients with CR all got ASCT for consolidation therapy. Till the end of follow-up, the 11 patients all survived with no diseaseprogression. However, for patients with high risk factors, the first-line ASCT treatment could not further improve the efficacy. With respect to the roles of first-line therapy with

Table 2. Adverse effects related to the treatment of the 20 patients

\begin{tabular}{lccccc}
\hline & $\begin{array}{c}\text { Myelosuppression } \\
(\text { III-IV) }\end{array}$ & $\begin{array}{c}\text { Impaired liver function } \\
(\text { ALT } \uparrow)\end{array}$ & $\begin{array}{c}\text { Adverse reactions of the } \\
\text { digestive system }\end{array}$ & Cardiac toxicity & Pulmonary infection \\
\hline Cases & 5 & 2 & 14 & 3 & 3 \\
$(\%)$ & 25 & 10 & 70 & 15 & 15 \\
\hline
\end{tabular}


ASCT in the high risk HL patients, it has been concluded in the HD01 study that there was no significant difference in OS and PFS between the ASCT treatment and the conventional chemotherapy. In this study, there were 11 patients (55\%) who underwent ASCT and remained disease-free at the time of follow-up. It is significantly suggested that the comprehensive treatment is more meaningful for patients with refractory relapse. It is reported that rituximab is effective in the treatment of CD20-positive nodular lymphocyte-predominant Hodgkin's lymphoma [11]. It was reported that after rituximab monotherapy for the recurrence of nodular sclerosis $\mathrm{HL}$, the total response rate was $22 \%$, the PR rate was $18 \%$, and the CR rate was $4 \%$. In addition, the total response rate was $19 \%$ for the 16 cases whose R-S cells did not express CD20 [12]. Thus, whether R-S cells express CD20 or not, rituximab is effective in recurrent HL patients. However, in this study, after 2 patients received combination chemotherapy of rituximab with ABVD, 1 case got SD and the other case got PD. The fact that neither of these 2 patients achieved the reported efficacy, was possibly due to the small sample size. More patients are needed to confirm the efficacy of rituximab in the treatment of HL patients with negative CD20.

With the development of new drugs, increasingly efficacy is shown in the treatment of refractory HL patients [13]. $\mathrm{BV}$ is a CD30 monoclonal antibody that cleaves intracellular proteolytic enzymes by binding to target cells, releasing MMAE (Monomethyl auristatin E). MMAE could bind to the microtubule system, leading to the apoptosis. A previous study showed that with 11 refractory HL patients who received $\mathrm{BV}$ as first-line treatment, 4 of them directly got CR, and6 got CR after ASCT treatment [14]. PD-1 inhibitors suppress the interaction with PD-L1 and PD-L2 by binding to PD-1, activating the antitumor activity of $\mathrm{T}$ cells $[15,16]$. Younes et al. reported a single-arm phase II trial of PD-1 inhibitors to treat CHL patients after ASCT or BV failure, that $9 \%$ got CR and $46 \%$ got PR [17].

In conclusion, for the refractory HL patients, comprehensive treatment including BV or PD-1 inhibitors should be actively utilized in the case of invalid second-line regimen.

\section{References}

[1] TOWNSEND W, LINCH D. Hodgkin's lymphoma in adults. Lancet 2012; 380: 836-847. https://doi.org/10.1016/S01406736(12)60035-X

[2] VAN DEN NESTE E, CASASNOVAS O, ANDRE M, TOUATI M, SENECAL D et al., Classical Hodgkin's lymphoma: the Lymphoma Study Association guidelines for relapsed and refractory adult patients eligible for transplant. Haematologica 2013; 98: 1185-1195. https://doi.org/10.3324/ haematol.2012.072090

[3] BROCKELMANN PJ, ANGELOPOULOU MK, VASSILAKOPOULOS TP. Prognostic factors in Hodgkin lymphoma. Semin Hematol 2016; 53: 155-164. https://doi.org/10.1053/j. seminhematol.2016.05.003
[4] HASENCLEVER D, DIEHL V. A prognostic score for advanced Hodgkin's disease. International Prognostic Factors Project on Advanced Hodgkin's Disease. N Engl J Med 1998; 339: 1506-1514. https://doi.org/10.1056/ NEJM199811193392104

[5] MOSKOWITZ CH, NIMER SD, ZELENETZ AD, TRIPPETT T, HEDRICK EE et al. A 2-step comprehensive high-dose chemoradiotherapy second-line program for relapsed and refractory Hodgkin disease: analysis by intent to treat and development of a prognostic model. Blood 2001; 97: 616-623. https://doi.org/10.1182/blood.V97.3.616

[6] RAMCHANDREN R. Advances in the treatment of relapsed or refractory Hodgkin's lymphoma. Oncologist 2012; 17: 367-376. https://doi.org/10.1634/theoncologist.2011-0258

[7] VON TRESCKOW B, MOSKOWITZ CH. Treatment of relapsed and refractory Hodgkin Lymphoma. Semin Hematol 2016; 53: 180-185. https://doi.org/10.1053/j.seminhematol.2016.05.010

[8] SUREDA A, PEREIRA MI, DREGER P; Lymphoma Working Party of the European Group for Blood and Marrow Transplantation. The role of hematopoietic stem cell transplantation in the treatment of relapsed/refractory Hodgkin's lymphoma. Curr Opin Oncol 2012; 24: 727-732. https://doi.org/10.1097/ CCO.0b013e328359557e

[9] DAVISON K, CHEN BE, KUKRETI V, COUBAN S, BENGER A et al. Treatment outcomes for older patients with relapsed/ refractory aggressive lymphoma receiving salvage chemotherapy and autologous stem cell transplantation are similar to younger patients: a subgroup analysis from the Phase III CCTG LY.12 Trial. Ann Oncol 2017; 28: 622-627. https://doi. org/10.1093/annonc/mdw653

[10] CZYZ A, LOJKO-DANKOWSKA A, DYTFELD D, NOWICKI A, GIL L et al. Prognostic factors and long-term outcome of autologous haematopoietic stem cell transplantation following a uniform-modified BEAM-conditioning regimen for patients with refractory or relapsed Hodgkin lymphoma: a single-center experience. Med Oncol 2013; 30: 611. https://doi.org/10.1007/ s12032-013-0611-y

[11] KASAMON YL, JACENE HA, GOCKE CD, SWINNEN LJ, GLADSTONE DE et al. Phase 2 study of rituximab-ABVD in classical Hodgkin lymphoma. Blood 2012; 119: 4129-4132. https://doi.org/10.1182/blood-2012-01-402792

[12] YOUNES A, ROMAGUERA J, HAGEMEISTER F, MCLAUGHLIN P, RODRIGUEZ MA et al. A pilot study of rituximab in patients with recurrent, classic Hodgkin disease. Cancer 2003; 98: 310-314. https://doi.org/10.1002/ cncr.11511

[13] GLIMELIUS I, DIEPSTRA A. Novel treatment concepts in Hodgkin lymphoma. J Intern Med 2017; 281:247-260. https:// doi.org/10.1111/joim.12582

[14] CHEN R, PALMER JM, MARTIN P, TSAI N, KIM Y et al. Results of a Multicenter Phase II Trial of Brentuximab Vedotin as Second-Line Therapy before Autologous Transplantation in Relapsed/Refractory Hodgkin Lymphoma. Biol Blood Marrow Transplant 2015; 21: 2136-2140. https://doi.org/10.1016/j. $\underline{\text { bbmt.2015.07.018 }}$ 
[15] VRANIC S, GHOSH N, KIMBROUGH J, BILALOVIC N, BENDER R et al. PD-L1 Status in Refractory Lymphomas. PLoS One 2016; 11: e0166266. https://doi.org/10.1371/journal. pone. 0166266

[16] GOODMAN A, PATEL SP, KURZROCK R. PD-1-PD-L1 immune-checkpoint blockade in B-cell lymphomas. Nat Rev Clin Oncol 2017; 14: 203-220. https://doi.org/10.1038/ nrclinonc. 2016.168
[17] YOUNES A, SANTORO A, SHIPP M, ZINZANI PL, TIMMERMAN JM et al. Nivolumab for classical Hodgkin's lymphoma after failure of both autologous stem-cell transplantation and brentuximab vedotin: a multicentre, multicohort, single-arm phase 2 trial. Lancet Oncol 2016; 17 : 1283-1294. https://doi.org/10.1016/S1470-2045(16)30167$\underline{X}$ 